\title{
6
}

\section{Physical Investigation of Discrete Air Pocket Migration and Release in CSO Storage Tunnels}

\author{
James W. Lewis, Steven J. Wright and Jose G. Vasconcelos
}

Various rapid filling scenarios lead to the formation of large discrete air pockets in below ground storage tunnel systems. The release of trapped air pockets through a vertical shaft can potentially cause a geyser event in which untreated wastewater returns to the ground surface. It is important to the design efforts of these expensive systems to estimate the potential for such events and to provide solutions to mitigate the undesirable effects. However, little is known about the behavior of discrete air pockets once they are trapped within tunnel systems. Initial laboratory experiments were performed to qualitatively assess the main contributing variables for the direction and velocity of air pockets as they migrate within nearly horizontal systems. Experimental data is collected for air pocket migration in the direction of water flow. Next, a diameter expansion within the vertical shaft was investigated as a possible design modification to mitigate geyser events. Experimental variables such as the ratio of expansion diameters and the vertical location of the expansion were investigated to optimize the proposed design. The scalability of experimental results was explored by performing tests on a $0.095 \mathrm{~m}$ diameter tunnel as well as a $0.203 \mathrm{~m}$ diameter tunnel. Qualitative conclusions are presented and discussed from the experimental results.

Lewis, J., S.J. Wright and J. Vasconcelos. 2010. "Physical Investigation of Discrete Air Pocket Migration and Release in CSO Storage Tunnels." Journal of Water Management Modeling R236-06. doi: 10.14796/JWMM.R236-06.

(C) CHI 2010 www.chijournal.org ISSN: 2292-6062 (Formerly in Dynamic Modeling of Urban Water Systems. ISBN: 978-0-9808853-3-0) 


\subsection{Introduction}

One strategy for preventing combined sewer overflows (CSOs) in urban areas is to construct large underground storage tunnels to temporarily detain the peak runoff flows. These storage tunnels may fill rapidly during large, infrequent, storm events and geysers have been witnessed in which an intense upward movement of air and liquid rises through a vertical shaft, lifting untreated wastewater beyond the grade elevation. The previous investigations by Wright et al. (2008) and Wright et al. (2009) discuss how the physical release of trapped air is capable of lifting water large vertical distances independent from pressure surges within the system. Independence of air-induced geyser events from pressure surges is confirmed in this study.

Air pockets are generally ventilated from surcharged CSO tunnels through manholes or other vertical shafts located throughout the system. The buoyant force of the air pocket is capable of transferring momentum to the liquid directly above it and lifting it significant distances. As the air pocket rises, it generally occupies the center of the shaft while the liquid flows downward around the outside (Davies and Taylor 1950). This creates a counter current shear flow between the rising air pocket and the thin film of liquid falling around the outside. In addition, there is another physical process known as flooding instability that may develop in which liquid is entrained in the upward accelerating air due to the large shear at the interface between the two counterflowing fluids. The study by Guedes de Carvalho et al. (2000) shows that flooding instability increases with larger diameter systems due to the potentially higher air velocities.

The rapid increase of inflow into CSO tunnels due to runoff is capable of producing free surface bores that propagate through the system. A pipe-filling bore fills the entire cross-section of the tunnel as it propagates. These bore fronts are capable of pushing a column of air ahead of them like a piston. Changes in the system geometry such as slope change, diameter change, gates, or valves can cause these bore fronts to pressurize a pocket of air ahead of them if ventilation is not properly designed.

Bores can also exist in which the pipe cross section is not fully filled but rather there is a gradual flow regime transition behind them. These gradual transitions may trap air pockets as they reflect off system boundaries or collide with one another. A description of other mechanisms for air pocket entrapment can be found in Vasconcelos and Wright (2006).

A modeling framework for simulating shock fronts associated with free surface bores has been developed by Vasconcelos et al. (2006). This numerical 
approach, known as the two component pressure approach (TPA), is capable of accurately resolving the bore fronts so that it is possible to determine the formation and location of air pockets in the system. Other common numerical models are unable to predict the possibility of air entrapment, and generally ignore the air's presence altogether.

Even with the TPA framework, understanding the subsequent behavior of air pockets following their formation is quite complicated. One reason is that propagation of large air pockets involves the formation of a sharp front where the conventional shallow water approximations (especially the assumption of hydrostatic pressure variations) are not applicable across the intrusion front. In addition, large air pockets sometimes break down into a number of smaller pockets. This breakdown is apparently associated with wave activity at the interface between the air pocket and the underlying water. More on this and air entrainment through hydraulic jumps can be found in the Ph.D. thesis of Estrada (2007).

In order to develop general guidance for preventing geyser events due to air pocket release, two main considerations were explored. First, the proper locations for ventilation shafts are important in preventing air build-up and pressurization. For sloping pipelines it is less than straightforward to determine the best location for ventilation since the air pocket may migrate down the slope due to inertia effects or upslope due to air buoyancy or inertia. The results of a preliminary investigation into the migration of air pockets are presented here.

Secondly, the mitigation of air-induced geyser events is explored by constructing a diameter expansion within the vertical shaft to dissipate the upward momentum. It is expected that the air will slow significantly as it reaches the upper, larger diameter pipe. Experimental tests are presented to confirm this design strategy.

A final objective of this study was to explore the limitations for scaling the small-scale laboratory results to larger scales. Underground CSO storage tunnels are constructed with sizes up to about $10 \mathrm{~m}$. Space constraints require significant reductions in scale to reproduce even portions of a tunnel system in a laboratory experiment. Scaling based on dimensionless numbers such as the Froude number has been studied carefully in fluid mechanics applications, but no assessment has been conducted specifically for CSO tunnels. Furthermore, it is possible that the air-water interactions may have differences at larger scales, as mentioned earlier with respect to flooding instability. A single test is performed to check the validity of Froude number scaling. 


\subsection{Experiments}

A physical model representing a conceptual portion of a CSO tunnel was constructed in the laboratory to explore the behavior of air migration and release. The schematic for the experimental setup is presented in Figure 6.1. A horizontal main tunnel was constructed of $6.4 \mathrm{~m}$ long and $0.0953 \mathrm{~m}$ diameter clear acrylic pipe. A large reservoir was used at the upstream end to maintain a relatively constant pressure within the pipeline. A $10.2 \mathrm{~cm}$ butterfly valve was used at the downstream end to regulate the water flow. An air injection hose was connected through the bottom of the pipe near the upstream end. A $4.45 \mathrm{~cm}$ diameter vertical riser was constructed $5.2 \mathrm{~m}$ from the air injection point, near the downstream end.

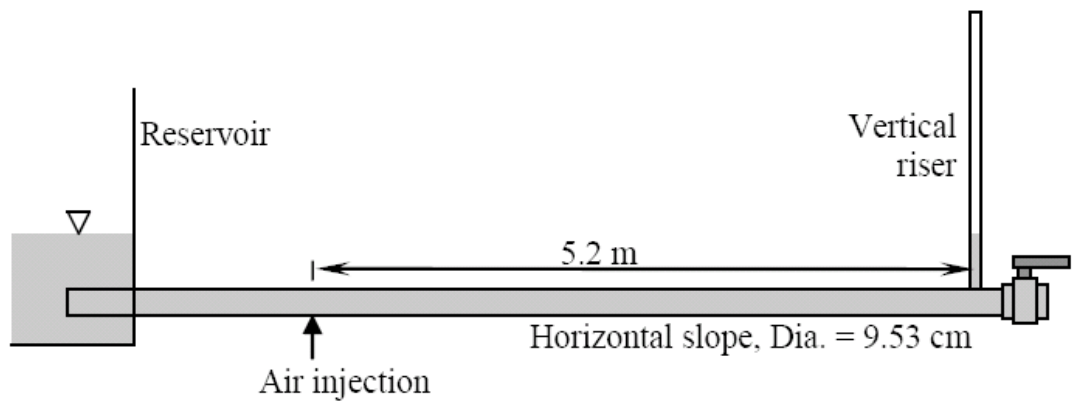

Figure 6.1 Schematic of experimental setup.

Simple air injection was used to show the independence of air-induced geyser strengths from pressure surge. The valve was completely closed to prevent water flow in the main tunnel and the initial water level was established in the upstream reservoir. The air inflow rate was adjusted to vary the strength of the geyser. Geyser strengths were observed using a digital video camera capable of 30 frames/s. Video recordings were $3 \mathrm{~min}$ to $5 \mathrm{~min}$ duration for each test. The water level within the vertical riser oscillated greatly as air pockets escaped up the riser; the geyser strength was defined as the maximum water level observed relative to the static water level. Two air inflow rates, of $0.136 \mathrm{~L} / \mathrm{s}$ and $0.87 \mathrm{~L} / \mathrm{s}$, were tested and peak geyser strengths were recorded.

A few specific air migration tests were performed to obtain a general idea of how air pockets migrate within a horizontal pipe tunnel. Two tests were performed in the $0.0953 \mathrm{~m}$ diameter tunnel at water flow rates of $1.22 \mathrm{~L} / \mathrm{s}$ and $2.02 \mathrm{~L} / \mathrm{s}$. A test window $25.4 \mathrm{~cm}$ long located approximately $1.8 \mathrm{~m}$ from the air injection point was used along with the digital video camera to measure the air 
pocket lengths and velocities. The air inflow rate was established for each test such that a range of bubble sizes would be carried through the test section.

The diameter expansion strategy for mitigating geyser events was also tested in the laboratory. Three variables were adjusted to observe their influence on geyser strength, namely the air inflow rate, the diameter expansion ratio, and the vertical location of the expansion within the riser. A constant diameter in the vertical riser of $4.45 \mathrm{~cm}$, or an expansion ratio of 1.0 , was taken from the geyser experiments above as the control condition. The same air inflow rates of $0.136 \mathrm{~L} / \mathrm{s}$ and $0.87 \mathrm{~L} / \mathrm{s}$ were used. Expansion ratios of 1.29, 2.14 and 3.00 were constructed using upper pipe diameters of $5.72 \mathrm{~cm}, 9.53 \mathrm{~cm}$ and $13.34 \mathrm{~cm}$ respectively. These expansions were tested at vertical distances of $40.3 \mathrm{~cm}$ and $101.3 \mathrm{~cm}$ above the invert of the main tunnel.

A larger scale experiment was constructed using a main tunnel diameter of $0.203 \mathrm{~m}$. The schematic for the experimental setup was the same as Figure 6.1 with the exception of the distance between air injection and the vertical riser. Two tests were performed for air migration using water flow rates of $14.4 \mathrm{~L} / \mathrm{s}$ and $16.0 \mathrm{~L} / \mathrm{s}$. Again, air pocket lengths and velocities were measured using a test window and digital video camera. These flow rates were not scaled to exactly match the small scale experiments but were performed to check the possible dimensionless relation between bubble size and velocity.

Froude number scaling was used to test a single geyser event scenario between the two scales. The length-scale ratio between the two diameter sizes is: $0.203: 0.095=2.1$. Volume flow rates scale with a power of 2.5 so an air flow of $0.136 \mathrm{~L} / \mathrm{s}$ in the small scale is multiplied by $2.1^{2.5}$ to get $0.87 \mathrm{~L} / \mathrm{s}$ air inflow for the larger scale. The resulting geyser strengths for each length scale were measured, again using the peak water level during $3 \mathrm{~min}$ to $5 \mathrm{~min}$ digitally recorded video.

\subsection{Results}

\subsubsection{Air-Induced Geysers}

The experiments revealed that air injection into a system at rest was capable of producing sizeable geyser strengths. The release of large air pockets was more capable of producing stronger geysers compared to smaller air pockets, even in rapid succession. A single, large air mass accelerated the water column above it in a swift motion whereas the rapid succession of air pockets broke up the vertical air-water interactions. 
As shown in Table 6.1, the air inflow rate of $0.136 \mathrm{~L} / \mathrm{s}$ was capable of producing a geyser strength of 4.9 times the diameter of the main tunnel (note: geyser strengths here are defined as the water rise beyond the initial static level). The air inflow rate of $0.87 \mathrm{~L} / \mathrm{s}$ produced a geyser strength of 12.7 times the tunnel diameter. This experimental evidence confirms the physical occurrence of geyser events resulting from air pocket release, independent of pressure surges within a CSO tunnel and confirms observations made in flowing systems (Wright et al. 2008) in which water was lifted large distances in vertical shafts due to the release of air pockets.

Table 6.1 Geyser strengths due to air injection $(9.53 \mathrm{~cm}$ tunnel diameter).

\begin{tabular}{cccc}
\hline $\begin{array}{c}\text { Air Inflow } \\
\text { Rate }(\mathrm{L} / \mathrm{s})\end{array}$ & $\begin{array}{c}\text { Static Water Level } \\
\text { (cm from invert) }\end{array}$ & $\begin{array}{c}\text { Peak Rise }(\mathrm{cm} \\
\text { from invert) }\end{array}$ & $\begin{array}{c}\text { Geyser strength (tunnel diameters } \\
\text { beyond static water level) }\end{array}$ \\
\hline 0.136 & 31.4 & 78 & 4.9 \\
0.87 & 31.4 & 152 & 12.7 \\
\hline
\end{tabular}

\subsubsection{Air Migration Results}

The air migration experiments also revealed some interesting observations. First, larger air bubbles migrated faster than smaller air bubbles. In addition, the air bubbles coalesced rather easily during translation, agreeing with the same trend discussed in Barnea and Taitel (1993). Secondly, small air bubbles generally traveled slower than the mean water velocity while larger air pockets traveled faster than the mean water velocity. A dimensionless relation is formed to represent the air pocket migration velocity as shown in Figure 6.2 using the air pocket velocity $(V a)$, mean water velocity $(V w)$, gravitational acceleration $(g)$, and the tunnel diameter $(D)$. Figure 6.2 shows not only the results of the $9.53 \mathrm{~cm}$ diameter pipe but also the $20.3 \mathrm{~cm}$ pipe.

The data clearly reveals an increasing air migration velocity as a function of air pocket size. It is reasonable to expect the velocity to level off, as indicated, as the air pocket size increases, approaching a migration velocity for an infinitely long air pocket.

Further work is planned to study the upstream migration of air pockets. Benjamin (1968) discusses the intrusion of an infinitely long air pocket in an emptying pipe and will be used for comparison with the upstream migration of large discrete air pockets. The experimental variables of water flow rate and air pocket size are expected to be influential. 


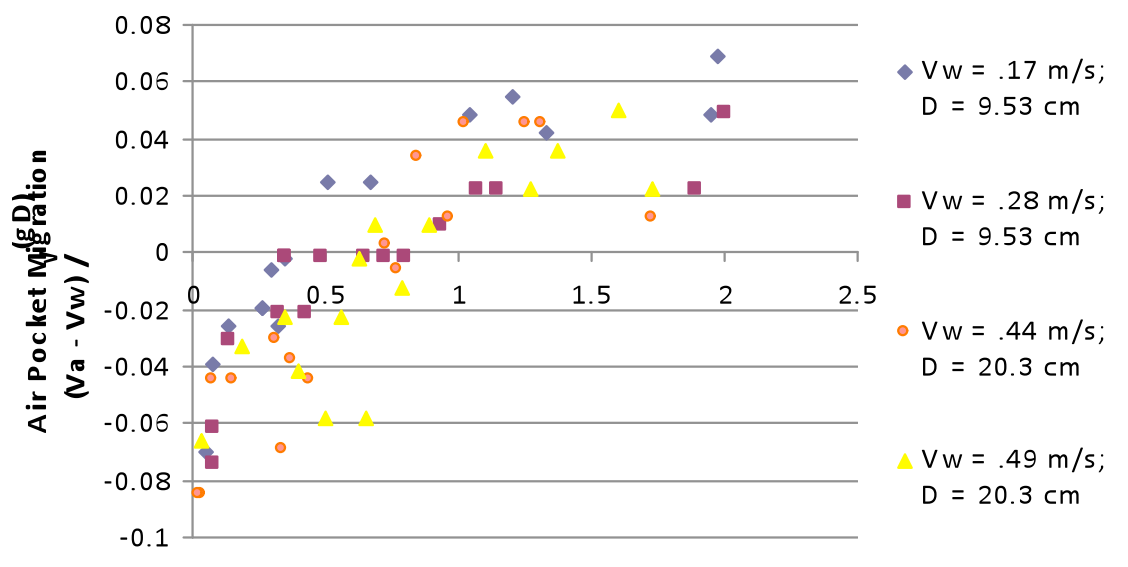

L / D (L: length of a ir pocket, D: dia meter of ma in tunnel)

Figure 6.2 Air pocket migration in the direction of water flow.

\subsubsection{Diameter Expansion Results}

The experimental results for the riser diameter expansion are presented in Table 6.2 and Figure 6.3. For the low air inflow rate of $0.136 \mathrm{~L} / \mathrm{s}$, the diameter expansion is quite effective in reducing the geyser strength. The expansion ratios of $1.29,2.14$ and 3.00 resulted in geyser strengths of $2.8,1.5$ and 1.3 respectively compared to a strength of 4.9 in a riser without expansion. Indeed, the two larger expansion ratios dissipate the geyser momentum such that the peak rise is only a short distance above the expansion location. The lower vertical location is more effective in reducing the geyser strengths than the higher vertical location, as more clearly seen in the higher air inflow tests. The low vertical expansion is successful in reducing the geyser strength from 12.7 down to only 3.1 times the main tunnel diameter. On the other hand, the higher vertical location is basically ineffective in reducing the maximum water rise within the geyser. Observations showed that the peak rise for the two larger expansions produce sprays of liquid rather than a horizontal water level, but the height of the spray stays the same as the control condition. This suggests that an expansion high within the vertical shaft will do very little to reduce geyser strengths. The expansion strategy appears successful for certain conditions but further study is needed before general recommendations can be made. 
Table 6.2 Data for riser diameter expansion experiments.

\begin{tabular}{cccccc}
\hline $\begin{array}{c}\text { Expansion } \\
\text { Ratio }\end{array}$ & $\begin{array}{c}\text { Vertical Loca- } \\
\text { tion (cm from } \\
\text { invert) }\end{array}$ & $\begin{array}{c}\text { Air Inflow } \\
\text { Rate (L/s) }\end{array}$ & $\begin{array}{c}\text { Static Water } \\
\text { Level (cm } \\
\text { from invert) }\end{array}$ & $\begin{array}{c}\text { Peak Rise } \\
\text { (cm from } \\
\text { invert) }\end{array}$ & $\begin{array}{c}\text { Geyser strength (tunnel } \\
\text { diameters above static } \\
\text { water level) }\end{array}$ \\
\hline 1.00 & 40.3 & 0.136 & 31.4 & 78 & 4.9 \\
1.29 & 40.3 & 0.136 & 31.4 & 58 & 2.8 \\
2.14 & 40.3 & 0.136 & 31.4 & 45 & 1.5 \\
3.00 & 40.3 & 0.136 & 31.4 & 44 & 1.3 \\
1.00 & 40.3 & 0.87 & 31.4 & 152 & 12.7 \\
1.29 & 40.3 & 0.87 & 31.4 & 101 & 7.3 \\
2.14 & 40.3 & 0.87 & 31.4 & 71 & 3.1 \\
3.00 & 40.3 & 0.87 & 31.4 & 61 & 12.7 \\
1.00 & 101.3 & 0.87 & 31.4 & 152 & 12.7 \\
1.29 & 101.3 & 0.87 & 31.4 & 152 & 12.7 \\
2.14 & 101.3 & 0.87 & 31.4 & 152 & 12.7 \\
3.00 & 101.3 & 0.87 & 31.4 & 152 & \\
\hline
\end{tabular}

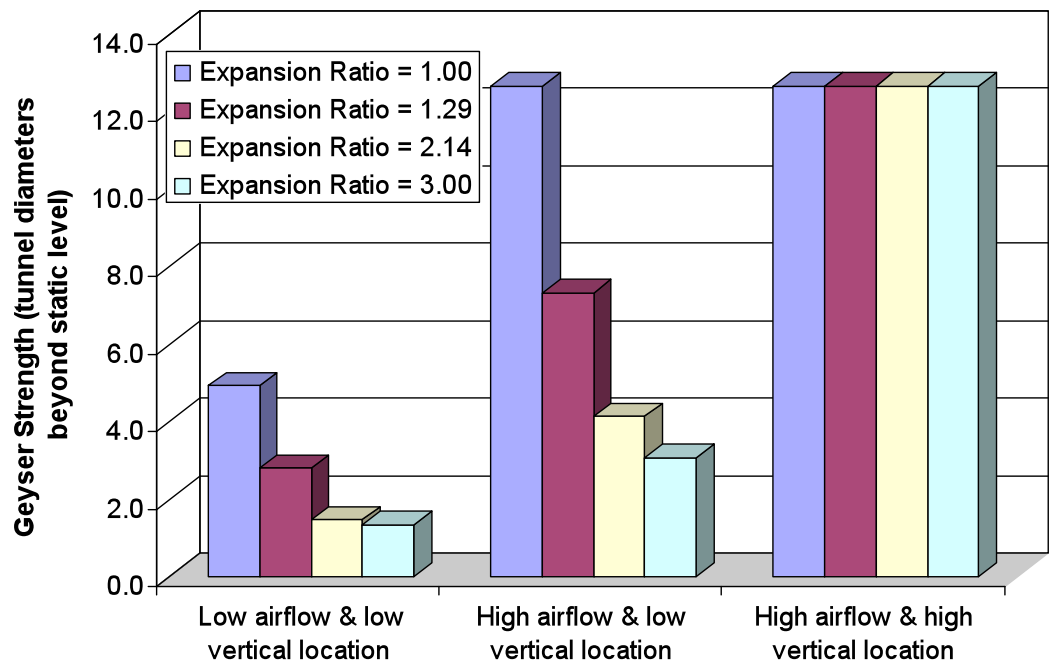

Figure 6.3 Riser diameter expansion results.

\subsubsection{Scaling Relations}

The $20.3 \mathrm{~cm}$ diameter pipe was used for preliminary comparison with the $9.53 \mathrm{~cm}$ diameter pipe. The results for an initial comparison between the two scales are shown in Table 6.3. If the geyser strength was directly scalable based 
on the diameter ratio between the two experiments, the peak rise from the larger scale would be roughly 2.1 times the height of the small scale. This is not the case, which preliminarily implies that geyser heights are not directly scalable. Further research is required in order to confirm the findings of these laboratory scale tests.

Table 6.3 Data for scaling experiments.

\begin{tabular}{ccccc}
\hline $\begin{array}{c}\text { Pipe Tunnel Diameter } \\
(\mathrm{cm})\end{array}$ & $\begin{array}{c}\text { Water } \\
\text { Flow }\end{array}$ & $\begin{array}{c}\text { Air Inflow Rate } \\
(\mathrm{L} / \mathrm{s})\end{array}$ & Riser Diameter $(\mathrm{cm})$ & $\begin{array}{c}\text { Peak Rise (cm } \\
\text { from invert) }\end{array}$ \\
\hline 9.53 & 0 & 0.136 & 4.45 & 78 \\
20.3 & 0 & 0.87 & 9.53 & 84 \\
\hline
\end{tabular}

\subsection{Conclusion}

This physical investigation was successful in highlighting a few qualitative conclusions for air behavior in CSO tunnels:

- Air release alone is capable of producing geyser events. This does not imply that traditional surge analyses should be neglected, but rather both possibilities should be addressed when designing for the worst-case scenario;

- The release of large air pockets is more capable of producing stronger geysers compared to smaller air pockets, even when those are in rapid succession;

- Air bubbles coalesce together easily as large air pockets generally overtake small air pockets. Air pockets are capable of migrating in the direction of flow at speeds greater than the velocity of the water;

- Diameter expansions within the vertical shaft are successful in reducing the strength of a geyser event under certain conditions. Diameter expansions just below the ground surface are expected to accomplish very little to mitigate a strong geyser event. However, diameter expansions constructed closer to the main tunnel are capable of reducing air-induced geyser events significantly, based on experimental results; and

- Preliminary investigations for scaling the laboratory results to prototype systems suggest significant scale effects but this issue requires further research. 


\section{Acknowledgment}

The authors would like to acknowledge the Washington, D.C., Water and Sewer Authority for providing financial support of this project.

\section{References}

Barnea, D. and Taitel, Y. (1993). "Model for slug length distribution in gas-liquid slug flow.” Int. J. Multiphase Flow, Volume 19, Number 5, pp. 829-838.

Benjamin, T. B. (1968). "Gravity currents and related phenomena." Journal of Fluid Mechanics, Volume 31, Issue 2, pp. 209-248.

Davies, R. M. and Taylor, G. I. (1950). "The Mechanics of Large Bubbles Rising Through Extended Liquids and through Liquids in Tubes." Proceedings of the Royal Society of London. Series A, Mathematical and Physical Sciences, Volume 200, pp. 375-390.

Estrada, O. P. (2007). "Investigation on the effects of entrained air in pipelines." Mitteilungen/Institut für Wasserbau, Universität Stuttgart: H. 158, Dissertation.

Guedes de Carvalho, J. R. F., Talaia, M. A. R., and Ferreira, M. J. F. (2000). "Flooding Instability of High-Density Gas Slugs Rising in Vertical Tubes Filled with Water." Chemical Engineering Science. Volume 55, pp. 3785-3802.

Vasconcelos, J. G. and Wright, S. J. (2006). "Mechanisms for air pocket entrapment in stormwater storage tunnels." Proceedings of World Water and Environmental Resources Congress - ASCE. Omaha, Nebraska, Paper 40856-14275.

Vasconcelos, J. G., Wright, S. J., and Roe, P. L. (2006). "Improved Simulation of Flow Regime Transition in Sewers: Two-component Pressure Approach.” Journal of Hydraulic Engineering, Volume 132, Issue 6, pp. 553-562.

Wright, S. J., Vasconcelos, J. G., Creech, C. T., and Lewis, J. W. (2008). "Flow regime transition mechanisms in rapidly filling stormwater storage tunnels." Environmental Fluid Mechanics, Springer Netherlands, Volume 8, pp. 605-616.

Wright, S.J., J. Vasconcelos, J. Lewis and C.T. Creech. 2009. "Flow Regime Transition and Air Entrapment in Combined Sewer Storage Tunnels." Journal of Water

Management Modeling R235-15. doi: 10.14796/JWMM.R235-15. 